\title{
Differences in encoding for free recall vs. recognition
}

\author{
JAMES W. HALL, LISA R. GROSSMAN, and KENT D. ELWOOD \\ Northwestern University, Evanston, Mlinois 60201
}

\begin{abstract}
Three experiments examined effects of test expectancy on memory for relatively unrelated words. In Experiment I, where preliminary recall or recognition practice was given, both recall and recognition were superior when the subjects expected and had practiced for recall. Free study led to better recall and recognition than paced presentation, but did not interact with test expectancy. Experiment II demonstrated that recall was better for subjects expecting a recall vs. a recognition test in the absence of preliminary practice. In Experiment III all subjects practiced both recall and recognition prior to presentation of the critical list. Study time also was varied. With longer study, recall was better when a recall test was expected, with no test expectancy effect on recognition. There were no appreciable expectancy effects with the short study period. Self-reports and other data suggested that the critical encoding differences produced by test expectancy manipulation were quantitative in nature.
\end{abstract}

The three experiments reported here concern possible differences in the way relatively unrelated words are encoded in the expectation of a free recall vs. a recognition memory test. This issue was attacked recently by Carey and Lockhart (1973) in an experiment involving free recall vs. recognition memory of word lists containing several instances of each of several categories, with category instances blocked during presentation. Recognition was better for subjects who expected a recognition test and had received prior recognition practice than for subjects who expected a recall test and had received prior recall practice. No overall difference in free recall as a function of test expectation and practice was found. However, for both recognition and recall the intracategory serial position functions differed markedly depending on expectation and prior practice. An experiment by Jacoby (1973) included conditions similar to those of Carey and Lockhart (1973), but failed to find differences in overall performance as a function of test expectancy and practice for either recall or recognition. The relevant serial position curves were not examined in that study, however, so it is not clear that the results are in complete contradiction. In any case, it would be unwise to generalize from data in which categorized lists are used to the more usual conditions wherein word lists have no particular organizational structure. As Postman has cautioned, "in the analysis of organizational processes, and in particular of the conditions of retrieval, it is not safe to assume that the same principles govern the processing and recall of categorized and of non-categorized lists" (Postman, 1972, p. 17).

This research was supported by Research Grant $2660-320$ to the first author from the National Institutes of Health. We are grateful for the assistance of Glen Masukawa and Sharon Madsen, and for the suggestions of Leo Postman and John Shaughnessy, who read a preliminary version of this paper. Requests for reprints should be sent to James W. Hall, Department of Psychology, Northwestern University, Evanston, Illinois 60201 .
Several other experiments also suggest substantial encoding differences for free recall vs. recognition, although the tasks involved differed considerably from those used in the three studies to be reported here. Tversky (1973) reported such differences in a series of experiments using picture-word stimuli, as did Bernbach (1973) and Loftus (1971) using paired associate tasks.

There are several theoretical lines that are relevant to the above question, one of these being the two-process theory of recall. That theory, as described by Kintsch (1968) views recall as requiring the operation of hoth a retrieval or memory search mechanism and a recognition decision or discrimination mechanism, whereas the recognition task requires only (or primarily) the latter. Assuming for the present, the essential validity of that position, there is some reason to expect that optimal modes of encoding will be different for the two tasks. Underwood (1969), in describing various attributes of words that may make up the memory for a particular word, has proposed that a record of situation frequency (the frequency attribute) may be particularly useful at the recognition decision stage, functioning as a discriminative cue but not as a retrieval cue. Data supporting the utility of frequency information for recognition subsequently were reported by Underwood and Freund (1970). Although Underwood (1969) had first proposed that the verbal associative attribute generally was useful only for retrieval, several recent studies (e.g., Hall \& Pierce, 1974; Zechmeister \& Gude, 1974) have suggested that verbal associative information can also play an important role in recognition memory.

The studies cited earlier by Carey and Lockhart (1973) and Tversky (1973), as well as Underwood's earlier analysis, suggest that encoding with heavy emphasis on the storage of verbal associative information may be more critical for recall than for recognition. Further, it is at least conceivable that the effective learner (e.g., the university student), given knowledge of the particular task demands, alters encoding opera- 
tions such that those attributes most relevant to the demands of the task are most heavily encoded. In the terms of Craik and Lockhart (1972), the subject might be more likely to enter into deeper processing in anticipation of a recall than of a recognition test, since, although the precise nature of "deeper processing" is somewhat vague, it seems to imply such processing as might be involved in searching for, and strengthening through rehearsal, associations among various words in a list.

\section{EXPERIMENT I}

In this experiment, college students were pretrained for three study-test trials in either free recall or recognition memory performance, then on the critical fourth list were either given the expected test or were unexpectedly given the alternate test. Within the above conditions, the lists were presented either in the usual experimenter-paced fashion or given to the subjects intact for free study. The latter variation was introduced because it was anticipated that whatever differences were found under paced presentation would be magnified under free study. That is, if subjects' control processes led to differing encoding in anticipation of recall vs. recognition, as suggested by Carey and Lockhart (1973), the free condition would maximize subjects' use of these differing processes. Finally, selfreport data concerning study strategies were gathered to provide assistance in identifying the nature of what. ever encoding differences might be found.

\section{Method}

Design and subjects. There were eight conditions formed by the orthogonal variation of the three independent variables: pretraining task and final test expectancy (free recall vs. recognition memory), presentation mode (paced presentation vs free study), and critical test type (free recall vs. recognition memory). The 240 subjects were students enrolled in Northwestern's introductory psychology course who participated in the experiment in fulfillment of a course requirement. The subjects were tested in groups of from 1 to 12 per session, and the groups were assigned eight conditions according to random procedures except to insure equal numbers (30) in the conditions.

Materials and procedure. All subjects were presented four consecutive study lists, each followed by either a free recall period or by a recognition memory test. For the paced presentation subjects were presented words on individual slides at a 5 -sec rate, whereas the free study subjects were each given a sheet of paper on which all words were typed in a single column. The four study lists contained $20,24,28$, and 31 items respectively. The total study times for the four lists were 100 , 120,140 , and $155 \mathrm{sec}$, respectively. Approximately one-fourth of the subjects in the free study conditions erroneously were given $160 \mathrm{sec}$ for study of the fourth list. However, no significant difference in performance was found between these subjects and those correctly given $155 \mathrm{sec}$ for study. The recognition tests consisted of the study words randomly interspersed with an equal number of distractors and displayed in two columns on a single sheet of paper. All words used in the experiment were selected randomly from five-, six-, and sevenletter nouns randomly chosen from the high-frequency (A and AA) and high-imagery (5.00-6.87) words from Paivio, Yuille, and Madigan (1968).

Half of the subjects were given study instructions for each of their four lists that informed them of a forthcoming free recall test, whereas the remainder were informed each time that a recognition memory test would be given. The tests actually given were consistent with the study instructions for all subjects except for the final critical list, at which point half of the subjects in each of these main groups were given the (unexpected) alternative test. For the recognition memory tests, the subjects were told to circle each word on the test sheet that was among those just presented. For free recall, the subjects were given a sheet with blank lines on which they were told to write as many of the words as they could. The test periods for the four lists were $2,2.33,2.67$, and $3 \mathrm{~min}$, respectively.

Following the final tist, all subjects completed a questionnaire concerning their study strategies. The first 11 items on the questionnaire consisted of brief descriptions of a series of possible study strategies gleaned from self-reports obtained in a previous pilot study. These descriptive statements were as follows: (1) repeated individual items over and over, (2) repeated items in a block of two, three or more, (3) read each item and tried to picture a scene with the item, (4) tried to use the word in association with another word in the list, (5) tried to use the word in association with another word not in the list, (6) used each item in a sentence by itself, (7) used groups of items in series to produce sentences, (8) tried to use the entire list in any order to make a story, (9) grouped the words in categories (e.g., animals, furniture, etc.), (10) grouped words according to the word size, letters, and sound similarity, and (11) grouped words according to their grammatical class. The subjects in dicated the extent to which each of the above study methods was used by means of a 7-point rating scale, with "l" indicating no use and " 7 " denoting extensive use. Below these items, the subjects also were asked to describe any other methods used and, finally, whether they would have studied the final list differently (and how) given their present knowledge.

\section{Results and Discussion}

As may be seen in Table 1, free recall was substantially better for subjects expecting free recall than for those expecting a recognition memory test $[F(1,116)=$ $31.86, \mathrm{p}<.001]$ and for those with free study vs. paced presentation $[F(1,116)=16.22, p<.001]$. The interaction did not approach significance $[F(1,116)<1.0]$. Of the two significant effects, it was the expectancypractice effect that was of primary interest here, since it indicated a very large recall advantage to those sub. jects expecting a recall test and, thus, was consistent with the reasoning outlined earlier. The absence of

Table 1

Mean Recall

\begin{tabular}{|c|c|c|c|c|c|}
\hline \multirow[b]{2}{*}{$\begin{array}{l}\text { Type of Test } \\
\text { Expected }\end{array}$} & \multicolumn{2}{|c|}{$\begin{array}{c}\text { Experiment } \\
\text { I } \\
150 \mathrm{sec}\end{array}$} & \multirow{2}{*}{$\begin{array}{c}\begin{array}{c}\text { Experiment } \\
\text { II } \\
150 \mathrm{sec}\end{array} \\
\begin{array}{c}\text { Paced } \\
\text { Only }\end{array}\end{array}$} & \multicolumn{2}{|c|}{$\begin{array}{l}\text { Experiment } \\
\text { III }\end{array}$} \\
\hline & $\begin{array}{l}\text { Paced } \\
\text { Study }\end{array}$ & $\begin{array}{l}\text { Free } \\
\text { Study }\end{array}$ & & Free & $\begin{array}{l}\text { Study } \\
\text { nly }\end{array}$ \\
\hline $\begin{array}{c}\text { Free Recall } \\
\overline{\mathrm{X}} \\
\mathrm{SD}\end{array}$ & $\begin{array}{r}12.73 \\
5.00\end{array}$ & $\begin{array}{r}16.57 \\
6.12\end{array}$ & $\begin{array}{r}13.56 \\
4.86\end{array}$ & $\begin{array}{r}12.85 \\
4.16\end{array}$ & $\begin{array}{r}17.10 \\
3.57\end{array}$ \\
\hline $\begin{array}{c}\text { Recognition } \\
\bar{X} \\
\text { SD }\end{array}$ & $\begin{array}{l}7.00 \\
5.01\end{array}$ & $\begin{array}{r}11.13 \\
5.46\end{array}$ & $\begin{array}{r}11.37 \\
3.40\end{array}$ & $\begin{array}{r}12.50 \\
4.26\end{array}$ & $\begin{array}{r}13.10 \\
6.08\end{array}$ \\
\hline
\end{tabular}


Table 2

Recognition Performance

\begin{tabular}{|c|c|c|c|c|c|c|c|c|}
\hline \multirow{3}{*}{$\begin{array}{c}\text { Test Practice } \\
\text { and Expectancy }\end{array}$} & \multicolumn{4}{|c|}{$\begin{array}{c}\text { Experiment I } \\
150 \mathrm{sec}\end{array}$} & \multicolumn{4}{|c|}{ Experiment III } \\
\hline & \multicolumn{2}{|c|}{ Paced Study } & \multicolumn{2}{|c|}{ Free Study } & \multicolumn{2}{|c|}{ Free Study } & \multicolumn{2}{|c|}{ Free Study } \\
\hline & Hits & FAs & Hits & FAs & Hits & FAs & Hits & FAs \\
\hline \multicolumn{9}{|l|}{ Free Recall } \\
\hline$\overline{\mathrm{X}}$ & 24.37 & 1.50 & 25.97 & 1.00 & 24.95 & 1.95 & 25.50 & \\
\hline SD & 4.91 & 1.98 & 3.95 & 1.39 & 3.89 & 2.67 & 4.98 & 1.92 \\
\hline \multicolumn{9}{|l|}{ Recognition } \\
\hline$\overline{\mathrm{X}}$ & 22.76 & 3.63 & 24.73 & 2.80 & 25.45 & 1.25 & 26.60 & 1.80 \\
\hline SD & 6.52 & 3.79 & 4.82 & 3.34 & 3.66 & 1.25 & 3.69 & 2.04 \\
\hline
\end{tabular}

any suggestion of an interaction between the variables was somewhat unexpected, since it had seemed sensible to expect subjects' control processes to operate most freely under free study, thus magnifying any test expectancy difference.

The recognition memory data shown in Table 2 indicate results paralleling those for free recall. The hit rate was highest and the false alarm rate lowest under free study and for subjects expecting a free recall test. Analysis of variance applied to hit/false alarm difference scores indicated significant main effects of both presentation mode $[\mathrm{F}(1,116)=4.24, \mathrm{p}<.05]$ and test expectation $[F(1,116)=8.09, p<.01]$, with no interaction $[F<1.0]$. Essentially identical results were obtained when that analysis was applied to $\mathrm{d}^{\prime}$ scores, the three $F$ values being, respectively, $4.21,8.95$, and $<1.0$. The finding of particular interest here was the superiority in recognition of subjects who expected free recall. The apparent lower magnitude of the various differences for recognition vs. recall is not amenable to interpretation, given the different metrics involved and the possibility of a ceiling effect for recognition.

What were the free recall subjects doing differently than those expecting a recognition test that resulted in such superior performance? The self-report data summarized in Table 3 provide some suggestions. That table includes mean ratings (and SDs) of extensiveness of use for the five study methods rated as most frequently used. These data appear generally consistent with the expectations described in our introduction, with simple item repetition being more common for recognition than for recall expectation and various item grouping methods more common for those expecting recall. When $t$ tests were applied to each of the 11 study categories (collapsed over presentation condition), significant differences $(p<.05)$ between recall and recognition expectation subjects were found for Study Categories 1, 2, and 4. Note, however, that for both conditions associative methods were reported more frequently used than was simple item repetition. For those subjects receiving a recall test, in the recognition expectancy condition $47 \%$ indicated that they would have studied differently given their knowledge following the final test, as compared to only $20 \%$ for the recall expectancy group $\left[\chi^{2}=9.60, p<.01\right]$. For subjects given a recognition test, the corresponding percentages were $13 \%$ and $10 \%$, respectively. Pearson correlation coefficients then were calculated to examine the relationship between critical test performance and reported use of the above five study methods within each of the four paced presentation conditions (see Table 4). The pattern of these correlations is similar for recall and recognition, and suggests that simple item repetition is weakly and negatively related to performance and

Table 3

Study Method Ratings: Experiment I

\begin{tabular}{|c|c|c|c|c|c|c|}
\hline \multirow[b]{2}{*}{$\begin{array}{c}\text { Test } \\
\text { Expectancy }\end{array}$} & \multirow[b]{2}{*}{$\begin{array}{c}\text { Presentation } \\
\text { Condition }\end{array}$} & \multicolumn{5}{|c|}{ Study Methods } \\
\hline & & $\begin{array}{l}\quad 1 \\
\text { Single Item } \\
\text { Repetition } \\
\end{array}$ & $\begin{array}{c}2 \\
\text { Item Blocks } \\
\text { Repetition }\end{array}$ & $\begin{array}{c}3 \\
\text { Imagery }\end{array}$ & $\begin{array}{c}4 \\
\text { Associated } \\
\text { with List }\end{array}$ & $\begin{array}{c}7 \\
\text { Items in } \\
\text { Sentences }\end{array}$ \\
\hline \multirow{5}{*}{ Free Recall } & Paced & & & & & \\
\hline & $\overline{\mathrm{X}}$ & 3.02 & 4.42 & 4.00 & 4.95 & 4.07 \\
\hline & $\begin{array}{c}\text { SD } \\
\text { Free }\end{array}$ & 1.85 & 1.97 & 2.18 & 1.83 & 2.35 \\
\hline & $\overline{\mathrm{X}}$ & 2.74 & 5.07 & 3.53 & 5.67 & 3.30 \\
\hline & SD & 1.85 & 1.97 & 2.10 & 1.70 & 2.26 \\
\hline \multirow{5}{*}{ Recognition } & Paced & & & & & \\
\hline & $\overline{\mathrm{X}}$ & 3.49 & 4.10 & 3.72 & 4.49 & 3.20 \\
\hline & $\begin{array}{l}\text { SD } \\
\text { Free }\end{array}$ & 1.84 & 2.11 & 2.25 & 1.89 & 2.26 \\
\hline & $\overline{\mathrm{X}}$ & 3.32 & 4.12 & 4.00 & 5.09 & 3.24 \\
\hline & SD & 1.97 & 2.22 & 2.29 & 2.13 & 2.47 \\
\hline
\end{tabular}


Table 4

Currelations of Reported Study Methods with Free Recall and Recognition (Paced Presentation)

\begin{tabular}{|c|c|c|c|c|c|c|}
\hline \multirow{2}{*}{$\begin{array}{c}\text { Critical } \\
\text { Test }\end{array}$} & \multirow{2}{*}{$\begin{array}{c}\text { Test } \\
\text { Expectancy }\end{array}$} & \multicolumn{5}{|c|}{ Study Methods } \\
\hline & & 1 & 2 & 3 & 4 & 7 \\
\hline Free Recall & $\begin{array}{l}\text { Free Recall } \\
\text { Recognition }\end{array}$ & $\begin{array}{c}\text { n.s. } \\
-.32 *\end{array}$ & $\begin{array}{l}\text { n.s. } \\
\text { n.s. }\end{array}$ & $\begin{array}{l}.50^{* *} \\
.29^{*}\end{array}$ & $\begin{array}{l}.57 * * \\
.60^{* *}\end{array}$ & $\begin{array}{l}\text { n.s. } \\
.53^{* *}\end{array}$ \\
\hline Recognition & $\begin{array}{l}\text { Free Recall } \\
\text { Recognition }\end{array}$ & $\begin{array}{c}\text { n.s. } \\
-.33^{* *}\end{array}$ & $\begin{array}{c}\text { n.s. } \\
-.30^{*}\end{array}$ & $\begin{array}{l}.60 \\
.31^{*}\end{array}$ & $\begin{array}{l}\text { n.s. } \\
.51 * *\end{array}$ & $\begin{array}{l}\text { n.s. } \\
\text { n.s. }\end{array}$ \\
\hline
\end{tabular}

that the attempt to form interitem associations is positively and fairly highly correlated with performance. The use of imagery also is positively related to performance on both tasks. These data are consistent with expectations insofar as free recall performance is concerned, but offer no support for the notion that recall and recognition call for qualitatively different encoding operations. The heavy use of associative processes and imagery during encoding appears to be effective for both tasks. Further discussion along these lines will follow our report of all three experiments.

If various conditions differed substantially in their encoding, then one might expect these differences to be reflected in the pattern as well as the level of recall, such that the serial position curves would differ substantially and item correlations would be relatively low. The functions shown in Figure 1 show this not to be the case. Note that these cannot be viewed as typical serial position curves in that the order of items was the same for all subjects; thus, specific items and list position are confounded. The single notable fact about the curves shown in Figure 1 is their striking similarity in form. That similarity is further reflected in the high correlations between the two expectancy conditions in terms of the frequency with which the various items were recalled, namely, .66 for the paced condition and .70 for the free study condition, ps $<.01$. In short, these more detailed analyses yield no evidence whatsoever of qualitative differences in processing among the various conditions.

The particular design of this experiment creates certain ambiguities in interpreting the recall differences described earlier. Our hypothesis focused on possible encoding differences as a function of test expectancy. However, an alternative explanation centers on retrieval. That is, the subjects in the nonswitch recall condition had received three prior lists in which retrieval as well as encoding practice was given, whereas the switch recall subjects had received no prior free recall tests. Could it then have been the additional retrieval practice that led to better final list performance for the nonswitch groups? The self-report data argue against such an interpretation, but perhaps not conclusively. A second limitation of the design also concerns differences in the practice list experience, namely, that the switch recall condition had been exposed to twice as many words as the nonswitch condition prior to exp sure to the final list. This occurred because the swit subjects received recognition tests for the first thr lists that included an equal number of new words distractors. Thus, the lower performance of the swits group may have been due to the proactive effects । prior study and test list items. Experiment II examint the effects on recall of manipulations in test expectan alone, omitting the practice list phase. Thus, using single test list, half the subjects were led to expect free recall test and half a recognition memory tes then all were tested for free recall. The omission practice also avoided the interpretive questions raise with respect to Experiment I.

\section{EXPERIMENT II}

In Experiment II subjects were given a single li under paced conditions, with instructions that led 1 either free recall expectation or recognition memol expectation. Then all subjects were given a free reca test.

\section{Method}

The same list of 31 words serving as the critical list in Expe1 ment I was presented to 54 Northwestern University student The words were individually presented on slides at a $5-\mathrm{sec}$ rat Then following a 1-min period devoted to the solution of arit metic problems, an unpaced free recall test was given. The su jects were tested in large groups, with all instructions containe in a test booklet provided them. For the switch subjects, the written instructions indicated that the test would require the to circle old words among many words on a test sheet. The no: switch subjects were told that they would be asked to wri down without cues all of the words they could remembe

\section{Results and Discussion}

Because the first slide was used to bring the projectc into focus, and thus was exposed for several addition: seconds, that item was omitted for data analysis, is ducing the number of words to 30 . The mean number of items recalled were 13.56 for the recall expectanc group and 11.37 for the recognition expectancy grour

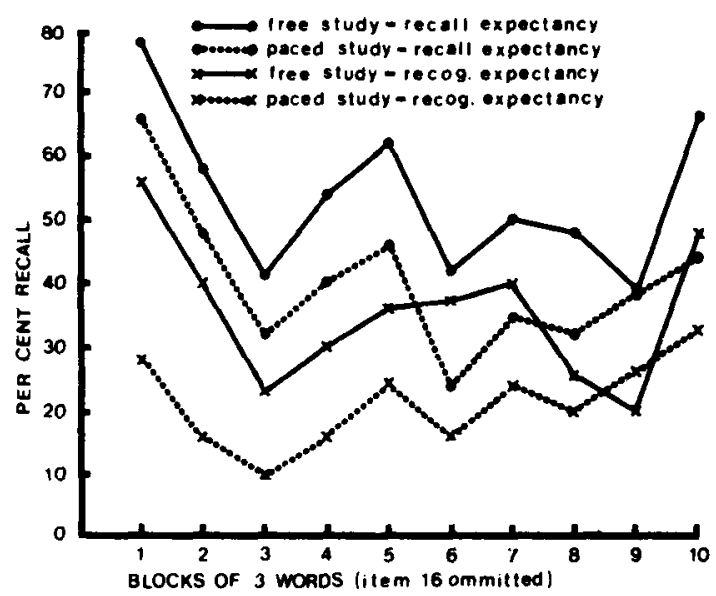

Figure 1. Free recall as a function of test expectancy and presentation method. 
The difference in items recalled for the two groups (see Table 1) was statistically significant $[\mathrm{t}(52)=2.09$, $p<.05$ ], though not nearly so large a difference as was found in Experiment I. The serial position-item curves again were similar in form, although not strikingly so as in Experiment I. The item correlation coefficient of $.43(\mathrm{p}<.05)$ was considerably lower than found in Experiment I, but not significantly so. The critical finding of this experiment is that the differential test expectancy in itself (i.e., without practice trials) was sufficient to produce a significant difference, albeit a small difference, in recall performance. However, the magnitude of that difference was small ( $45 \%$ recall for the recall expectancy condition vs. $38 \%$ recall for the recognition expectancy condition). Experiment III reinstated the use of practice lists, but made that practice identical for the two expectancy conditions. In addition, the effect of amount of study time was investigated.

\section{EXPERIMENT III}

In this experiment, all subjects were given two practice lists, one for recognition and one for recall, prior to presentation of the critical list. On the critical list, subjects were given either a free recall or a recog. nition test. Within each of these conditions, that test was expected by half the subjects and unexpected by the remainder. This procedure was designed to allow subjects to acquire a fuller notion of the task demands than might have been possible in Experiment II, while avoiding the interpretive difficulties of Experiment I by insuring that the pretraining was identical for both expectancy conditions. It was expected that the recall performance differences found in Experiment II would appear in magnified form. In addition, half of the subjects in each of these conditions were given reduced study time ( $90 \mathrm{sec}$ vs. $180 \mathrm{sec}$ on the critical list). It was expected that such a reduction in study time would decrease the test-expectancy effect for free recall, since subjects would have considerably less opportunity to apply the control processes that presumably led to the differential encoding observed earlier.

\footnotetext{
Method

The subjects were 160 Northwestern students who served to fulfill a requirement for their introductory psychology course. All subjects received two practice lists, one under free recall conditions and the other under recognition instructions with task order counterbalanced (i.e., half the subjects received the recall practice task first). For each list order condition, half of the subjects were given free recall instructions for study of the critical (third) list and half were given recognition instructions. Half of the subjects in each of those four conditions were given $90-\mathrm{sec}$ study periods for each list and the remainder were given 180 -sec study periods. The first two study lists consisted of 28 items each, and were similar to two of the practice lists used in Experiment $I$, as were the recognition tests for those lists. The critical third list and the recognition test for that list were identical to those used for the critical list in the previous experiments. All study lists were presented as in the free study condition in Experiment I.
}

Within each of the eight conditions just described, half of the subjects were tested on List 3 in accordance with their study instructions and half were switched to the alternate test, bringing the number of conditions to 16 in total. These conditions resulted from the orthogonal variation of practice task order, study time, critical list study instructions, and type of critical test. Testing was done in groups of 2 to 10 subjects, and testing groups were assigned to the 16 conditions in a predetermined random order except to insure the assignment of 10 subjects to each cell.

\section{Results and Discussion}

Significant effects on recall performance were found for both critical test expectancy $[F(1,72)=5.49$, $\mathrm{p}<.05]$ and study time $[\mathrm{F}(1,22)=6.83, \mathrm{p}<.05]$, with no difference between the two practice orders. The relevant means are shown in Table 1 . The predicted interaction reflecting a greater superiority of the recall expectancy conditions with a longer study period was marginally reliable $[F(1,72)=3.87, .10>p>.05]$. Note that the difference in percentage recalled between the two expectancy conditions with the longer study period was considerably higher than in Experiment II and similar to that in Experiment I. The item correlation in the 180-sec condition between expectancy groups was $.48(\mathrm{p}<.05)$, a lower relationship than found in Experiment I, but not significantly so.

As shown in Table 2, recognition performance was slightly higher under the expectancy of a recognition test and with the longer study period. None of the experimental variables produced effects approaching significance using either the hit/false alarm difference scores or the $\mathrm{d}^{\prime}$ scores. The absence of a significant recognition difference between test expectancy conditions (and the fact that the slight difference favors the recognition expectancy condition) stands in contrast with the results of Experiment I, where the recall expectancy condition was superior. The fact that recog. nition did not significantly improve with increased study may have been the result of a ceiling effect.

\section{GENERAL DISCUSSION}

Together the experiments are convincing in demonstrating effects of test expectation on free recall. Moreover, the greater magnitude of that effect in Experiments I and III, compared with Experiment II, indicates that prior practice on the relevant tasks increases the performance differences between test expectancy conditions. The mechanisms involved in that increase are not clear. Possibly the practice allows subjects to acquire differing processing strategies, as suggested by Carey and Lockhart (1973), although it seems more likely that such strategies would be of preexperimental origin, with the practice trials offering the opportunity to retrieve and polish the strategies. Or the practice trials may simply better inform the subjects of the precise demands of the tasks, so that more effective strategy selection (rather than acquisition) may occur. 
The effects of test expectancy on recognition are less clear. Experiment I indicated that recognition was better when subjects prepared for a recall test, whereas a slight (nonsignificant) difference in the opposite direction was found in Experiment III. The most likely source of these contradictory results seems to be the difference in amount of recognition practice between the experiments, a point on which we shall elaborate shortly.

What of the nature of the encoding differences between the two tasks? Overall the data seem most consistent with the position that such differences were primarily quantitative rather than qualitative in nature. First, there was no hint, in Experiment I, of an interaction between presentation mode and test expectancy. If the encoding differences were qualitative, one would anticipate such an interaction, since the opportunity for the necessary strategies to be used was far greater under free study conditions. Second, the item correlations between conditions were higher than probably would be expected with substantial qualitative differences in encoding operations. The absence of test expectancy effects under the shorter study condition in Experiment III is consistent with the interpretation that the recognition expectancy subjects perceived that task as requiring less attention or processing and simply gave less attention to the task, particularly after the first minute or so.

The self-report data suggest that the recall expectancy subjects used associative processes more frequently and simple item repetition less frequently than did recognition expectancy subjects. It would not be accurate, though, to characterize the two conditions as using different encoding operations, since associative methods were reported as more extensively used under both conditions. Only $11 \%$ of the subjects in the recognition expectation condition and $6 \%$ in the recall condition reported no attempt whatsoever to link study items together for study (Method 4), whereas $20 \%$ and $28 \%$ of these two groups, respectively, indicated no simple item rehearsal (Method 1). Most subjects apparently process similarly except for quantitative differences, with, perhaps, a small minority of subjects displaying qualitative differences in encoding. Did those few subjects account for the overall performance differences found between expectancy conditions? A comparison of performance including only subjects who reported fairly extensive use of associative processes (ratings of 5 or higher on Study Method 4) shows that not to be the case. All means are higher, but the differences among conditions remains nearly the same. The similarity between recall and recognition in the patterns of correlations between study method ratings and performance also suggest primarily quantitative encoding differences. Thus, the self-report data do not indicate extensive qualitative encoding differences between recall and recognition, nor do they suggest that the qualitative differences that may exist are important determinants of the performance differences found.
In contrast to our conclusions, the experiments by Carey and Lockhart (1973) and Tversky (1973) citer earlier led those investigators to conclude that very sub stantial qualitative differences in encoding are optima for recall vs. recognition. Lockhart and Carey referrec to the use of different control processes for the twe tasks, and Tversky concluded that "recognition is en hanced by integration of the details of each item whil recall is enhanced by interrelating the items within : list." The experiments we have just reported do no indicate such marked encoding differences. We suspec that the difference between findings is chiefly a resul of differences in the nature of the recognition test: employed. In the experiments by Carey and Lockhart the foils in the recognition test were members of the same categories as were the target items, thus negating the value of associative and conceptual information The foils in the Tversky experiments were picture: bearing the same verbal labels and differing only ir pictorial detail, again decreasing the utility of verba associative information for recognition decisions. How ever, when, as in the present experiments, distractor: were not associatively confusable with target items verbal associative information evidently was useful fol recognition decisions and subjects did in fact encodt such information.

The precise role of the practice trials remains unclear Any or all of three outcomes (mentioned earlier) of practice may have occurred to account for certain of the differences within and between experiments. First encoding may have become in some sense more efficien 1 as a result of additional practice, especially when the task demands were high, as with recall testing. The in creased efficiency could simply amount to greater atten tion to the task. Second, for those subjects given recall pretests, the retrieval practice may have led to increas. ingly effective retrieval strategies. Finally, the practice trials very likely produced some deleterious proactive effects on final list performance, and such effects probably were greatest for those subjects exposed to the greatest number of items during practice, namely, the recognition practice subjects. The sorting out ot these possibilities will require additional experimentation.

Although not central to the purpose of these studies, the marked similarity in serial position-item curves between the free study and the pace presentation conditions seems noteworthy. A view of the learner as a highly active, flexible, resourceful strategist seems likely to lead one to expect marked differences in those functions reflecting the greater freedom under free study conditions. For example, under those conditions a subject could search the list for interitem similarities (bases for subjective organization) with minimal memory demands, since all items remained exposed throughout study. And, in general, the subjects' distribution of their study time among items might be expected to be quite different when they were in complete control of that distribution than when it was heavily determined by the experimenter. Thus, one would expect not only 
the observed difference in the level of performance, but also a difference in the pattern of performance. In light of present findings, such a view seems to overestimate the degree of control that subjects exercise over the nature of their information processing for memory.

\section{REFERENCES}

Bernbach, H. A. Processing strategies for recognition and recall. Journal of Experimental Psychology, 1973, 99 409.412.

Carey, S. T., \& Lockhart, R. S. Encoding differences in recognition and recall. Memory \& Cognition. 1973, 1. 297.300 .

Craik, F. I. M., \& Lockhart, R. S. Levels of processing: A framework for memory research. Joumal of Verbal Learning and Verbal Behavior. 1972, 11, 671-684.

Hall, J. W., \& Prerce, J. W. Recognition and recall by children and adults as a function of variations in memory encoding instructions. Memory \& Cognition, 1974, 2, $585-590$.

JACOBY, L. L. Test appropriate strategies in retention of categorized lists. Joumal of Verbal Leaming and Verbal Behavior, 1973, 12, 675-682.
Kintsch, W. Recognition and free recall of organized lists. Journal of Experimental Psychology, 1968, 78, 481-487.

LofTUs, G. R. Comparison of recognition and recall in a continuous memory task. Journal of Experimental Psychology, 1971, 91, 220-226.

Paivio, A., Yuille, J. C., \& Madigan, S. Concreteness, imagery and meaningfulness values for 925 nouns. Journal of Experimental Psychology, 1968, 76, 10-25.

Postman, L. A pragmatic view of organization theory. In E. Tulving \& W. Donaldson, (Eds.). Organization of memory. New York: Academic Press, 1972.

TVERsky, B. Encoding processes in recognition and recall. Cognitive Psychology, 1973, 5, 275-287.

UNDERWOOD, B. J. Attributes of memory. Psychological Review, 1969. 76. 559-573.

Underwood. B. J.. \& Freund, J. S. Testing effects in the recognition of words. Joumal of Verbal Learning and Verbal Behavior, 1970, 9, 117-125.

Zechmeister. E. B., \& Gude, C. Instruction effects in recognition memory. Bulletin of the Psychonomic Society. 1974, 3, 13-15

(Received for publication September 23, 1975; revision accepted Janúary 5,1976 .) 